\title{
Audiologic characteristics of patients with diabetes mellitus type 2
}

\section{Características audiológicas de pacientes com diabetes mellitus tipo 2}

\author{
Juliana Mota Ferreira(1) \\ Marília Fontenele e Silva Câmara(2) \\ Paulo César de Almeida ${ }^{(3)}$ \\ José Brandão Neto(1) \\ Carlos Antonio Bruno da Silva(2)
}

\footnotetext{
(1) Universidade Federal do Rio Grande do Norte - UFRN - Natal (RN), Brasil.

(2) Universidade de Fortaleza - UNIFOR Fortaleza (CE), Brasil.

(3) Universidade Estadual do Ceará - UECE - Fortaleza (CE), Brasil.

Source: Fundação Cearense de Apoio ao Desenvolvimento Científico e Tecnológico - FUNCAP
}

Conflict of interest: non-existent

Received on: December 23, 2015 Accepted on: June 10, 2016

\section{Mailing address:}

Carlos Antonio Bruno da Silva

Universidade de Fortaleza, Programa de Pós Graduação em Saúde Coletiva Av. Washington Soares, 1321, Bloco S,

Sala S-11, Edson Queiroz

Fortaleza - CE - Brasil

CEP: 60811-904

E-mail: carlosbruno@unifor.br

\section{ABSTRACT}

Purpose: to identify the audiological characteristics of patients with type 2 diabetes mellitus.

Methods: Cross-sectional study in secondary care unit for diabetes in Fortaleza, April-July 2010. The sample comprised 152 patients with type 2 diabetes, regardless of sex, between 36 and 60 years of age. Held pure tone audiometry (PTA), transient-evoked otoacoustic emissions (TEOAE) and distortion product otoacoustic emissions (DPOAE).

Results: association of age and time of diagnosis with hearing loss, and the time of diagnosis with the absence of DPOAE. It was observed sensorineural hearing loss in $63.2 \%$ of patients, which $71.9 \%$ were bilateral and $75 \%$ symmetric. Approximately $50 \%$ of hearing loss had flat configuration. TOAEs were absent in $75 \%$ of the patients and DPOAE in $78.9 \%$. There were no otoacoustic emissions in the presence of normal PTA, on average, $32 \%$ of the patients on the right and $48 \%$ on the left. The presence of otoacoustic emissions on the occurrence of hearing loss was observed in approximately $30 \%$ of patients for TEOAE and $14 \%$ for DPOAE on the right; and $25 \%$ for TEOAE and $11 \%$ for DPOAE on the left.

Conclusions: Prevalence of symmetrical bilateral sensorineural hearing loss with a flat configuration, and absence of TEOAE and DPOAE. The association analysis of the results of PTA and OAE suggests loss of outer hair cells of the cochlea or possible auditory neuropathy. These findings justify the hearing monitoring of these patients, as well as conducting specific tests to evaluate the central auditory system.

Keywords: Diabetes Mellitus, Type 2; Hearing; Evaluation; Audiometry; Cochlea

\section{RESUMO}

Objetivo: identificar as características audiológicas de pacientes com diabetes mellitus tipo 2.

Métodos: estudo transversal, realizado em unidade de atenção secundária para diabetes em Fortaleza, de abril a julho de 2010. Amostra composta por 152 pacientes diabéticos tipo 2, independente do sexo, entre 36 e 60 anos. Realizou-se audiometria tonal liminar (ATL), emissões otoacústicas evocadas por estímulo transiente (EOAT) e emissões otoacústicas evocadas-produto de distorção (EOAPD).

Resultados: associação da idade e do tempo de diagnóstico com a presença de perda auditiva, e do tempo de diagnóstico com a ausência de EOAPD. Observou-se perda auditiva sensorioneural em $63,2 \%$ dos pacientes, das quais $71,9 \%$ eram bilaterais e $75 \%$ simétricas. Aproximadamente, $50 \%$ das perdas auditivas apresentaram configuração plana. As EOAT estavam ausentes em $75 \%$ dos pacientes e as EOAPD em 78,9\%. Houve ausência de emissões otoacústicas na presença de ATL normal, em média, em $32 \%$ dos pacientes à direita e $48 \%$ à esquerda. Já a presença de emissões otoacústicas na ocorrência de perda auditiva foi observada em, aproximadamente, 30\% dos pacientes para EOAT e 14\% para EOAPD à direita; e 25\% para EOAT e 11\% para EOAPD à esquerda.

Conclusão: predomínio de perda auditiva sensorioneural bilateral simétrica com configuração plana, e ausência de EOAT e EOAPD. A análise da associação dos resultados da ATL e das emissões otoacústicas sugere prejuízo das células ciliadas externas da cóclea ou possível neuropatia auditiva. Tais achados justificariam o monitoramento da audição destes pacientes, bem como a realização de testes específicos para avaliação do sistema auditivo central.

Descritores: Diabetes Mellitus Tipo 2; Audição; Avaliação; Audiometria; Cóclea 


\section{INTRODUCTION}

Diabetes mellitus (DM) is a metabolic disorder characterized by hyperglycemic resulting from defects of the secretion and/or action of insulin, which can cause a variety of metabolic, neurological and vascular complications ${ }^{1,2}$.

It is estimated that 1out of every 11 individuals worldwide has diabetes, and Brazil is the fourth country in number of people affected between 20-79 years old, with 14.3 millions $^{3}$. The type $2 \mathrm{DM}$ is the most common, representing approximately $90 \%$ of all cases of the disease, affecting mainly middle-aged and elderly individuals ${ }^{4}$.

People with diabetes are at increased risk of developing chronic health complications. Constant blood glucose levels can affect the heart and blood vessels, eyes, kidneys and nerves ${ }^{3}$. Changes in the inner ear are also identified in some studies, in which they observed changes in the basement membrane of the capillaries of the vascular stria and the basilar membrane, remarkably thickened, giving rise to diabetic microangiopathy ${ }^{5}$.

It is believed that one of the causes of hearing loss in individuals with DM is a microangiopathy, which can interfere with the supply of nutrients and oxygen from the cochlea. And can be directly on the reduction of transport caused by the thickening of the walls of the capillaries, and indirectly, by reducing the flow due to vascular narrowing, leading to the death of cells and biological tissues. In addition to the cochlear, changes the DM can also cause secondary degeneration of the eighth cranial nerve, provoking neural hearing loss ${ }^{6}$.

The association between DM and hearing alteration is pointed to in several studies ${ }^{7,8}$ that found high audiometric thresholds ${ }^{2,9}$ and change in response of otoacoustic emissions (OAEs) ${ }^{2,10}$ in diabetic patients. The DM is also associated with increased risk of developing sensorioneural sudden hearing loss ${ }^{11}$.

Even though there is vast literature that points to the DM with auditory alterations, there is still no consensus among the related findings to the audiologic profile. Some studies indicate sensorioneural hearing loss at high frequencies ${ }^{12,13}$, while others have found low and medium frequencies deficit ${ }^{14}$. Studies involving the analysis of the OAE are also diverging to findings, while some showed reduction of amplitude of responses in diabetic patients ${ }^{2,15}$; others found no significant difference between the groups with DM and the control ${ }^{16}$.

Specific tests for hearing are not part of routine tests for diabetic patient care ${ }^{1,17}$. Whereas the hearing loss caused by the type $2 \mathrm{DM}$ can be prevented ${ }^{17}$, the development of research related to auditory function in DM would assist in raising awareness among health professionals about the necessary referrals.

On the above, the present study sought to identify the characteristics of patients with DM type audiologic 2, through the pure tone audiometry (PTA) and transient-evoked otoacoustic emission (TEOAE) and distortion product otoacoustic emissions (DPOAE).

\section{METHODS}

The study was approved by the Ethics and Research Committee of the Universidade de Fortaleza and registered with the mien $n^{\circ} 384 / 08$. All subjects involved in research have signed the "informed consent free and cleared", allowing, thus, with the completion and dissemination of this research and its results as Resolution 196/96.

Study, analytical, quantitative approach, carried out in secondary attention unit for the care in diabetes in Fortaleza. The sample was composed of 152 patients with type $2 \mathrm{DM}$, selected randomly, regardless of sex, with ages varying between 36 and 60 years of age, in the period from April to July 2010. All patients were evaluated with clinical monitoring of the disease in the institution, being in treatment with oral hypoglycemics or insulin.

Excluded from the research were patients with altered meatoscopy at the time of evaluation; with a history of middle ear infections; and who have other risk factors for hearing loss, among them: exposure to noise and/or ototoxic chemicals; severe cranial injury; history of infectious diseases; radiotherapy in head and neck and chemotherapy; family history of hearing loss.

Considering the prevalence of hearing loss increases with age ${ }^{18}$ were excluded patients above 60 years old, thus seeking to reduce the chances of natural aging of hearing (presbycusis) in the sample selected.

Selected patients were referred to the rehabilitation of the institution, to the achievement of the audiologic evaluation, being composed of PTA, TEOAE and DPOAE, preceded by the inspection of the external acoustic meatus, for investigation of possible changes that could interfere with the result of the evaluation.

PTA was chosen for being the standard test, responsible for detecting changes in hearing thresholds that occur from lesions in the inner ciliated cells and/or change in central hearing. The TEOAE and DPOAE were used by being able to identify changes resulting from dysfunction of external auditory ciliated cells of the 
cochlea (sub-clinical), sensory changes even before these were verified on audiometry ${ }^{2}$.

Instruments for data collection used were the form of an audiologic anamnesis and the chart of the health unit, being analyzed the following variables: sex, age, time of diabetes diagnosis, presence of hearing complaints and complaint type.

Variables related to hearing-the presence of hearing loss, type and degree of hearing loss audiogram configuration, and the presence of otoacoustic emissions, were analyzed according to the audiological evaluation results.

\section{Audiological evaluation}

For the audiologic evaluation the following instruments were used: Otoscope Heine brand, mini model 2000; audiometer Vibrasom brand, model AVS 500; otoacoustic emissions Vivosonic brand, model vivo 200DPS; audiometric cabin Redusom brand, all properly calibrated.

In the PTA it was searched the air passage thresholds, in the frequencies of $0.25 ; 0.5 ; 1 ; 2 ; 3 ; 4 ; 6$ and $8 \mathrm{kHz}$, and in bone via, in the frequencies of 0.5 ; 1; 2; 3 and $4 \mathrm{kHz}$, being considered normal thresholds to $25 \mathrm{dBNA}$. The results were classified according to the presence of hearing loss, type and degree of loss, the presence of hearing loss in isolated frequency, laterality ${ }^{19,20}$ audiogram configuration and symmetry of alteration ${ }^{21}$.

The hearing classification was held by the ear, considering normal when all the frequencies presented values less than or equal to $25 \mathrm{dBNA}$; and by individual, using the same criteria and considering normal when both ears showed values within the normal range.

The TEOAE were performed with click stimulus, which occurs predominantly in the range of 0.5 to 4 $\mathrm{kHz}$, in the intensity of $84 \mathrm{~dB}$ NPS, $11 \mathrm{~ms}$ window, in the frequency bands of $1,2,3$ and $4 \mathrm{kHz}$. The general reproducibility was observed, considered normal when more than $50 \%$, and the relation signal/noise, whereas emissions present when the result was greater than or equal to $3 \mathrm{~dB}^{22}$.

For the DPOAE two pure tones of different frequencies, presented simultaneously ( $\mathrm{F} 1$ and $\mathrm{F} 2$, $\mathrm{F} 2 / \mathrm{F} 1=1.22$ ) were used, with intensities of $\mathrm{F} 1$ and F2, respectively, 65dB NPS (L1) and 55dB NPS (L2). Frequencies $1.5 ; 2 ; 2.5 ; 3 ; 3.2 ; 3.5 ; 4 ; 4.5 ; 5 ; 5.5 ; 6 ; 7$ and $8 \mathrm{kHz}$ were analyzed, being considered present emissions when the signal/noise was greater than or equal to $6 \mathrm{~dB}^{22}$.
Otoacoustic emissions classification was realized per ear, considering present when all the frequencies presented normal values, according to the criteria previously described; and per individual, using the same criteria and considering the presence of emissions when both ears showed values within the normal range.

\section{Analysis of the data}

Data were analyzed according to averages, standard deviation and proportions. To compare the averages used the student t-test, and to verify the binding between the averages, we used the Chi-square test. To verify the association between the variables used the Chi-square test, the calculation of the ratio of chance and the confidence interval. For all the testing it was settled the significance level of $5 \%$.

The data was tabulated and analyzed in the program SPSS (Statistical Package for the Social Sciences -SPSS version 15.0).

\section{RESULTS}

152 patients were evaluated with DM, of which $57(37.5 \%)$ were male and 95 (62.5\%) female. The average age was 53.4 years of age $(S D=6.02)$, with predominance of aged 51 to 60 years, with 109 (71.7\%) evaluated patients, and $43(28.3 \%)$ aged 36 to 50 years.

The average time from diagnosis of DM was 11.2 years $(S D=6.3)$, with $97(64.2 \%)$ patients diagnosed between 1 and 12 years, and 54 (35.8\%) patients with between 13 and 33 years of age.

The findings related to the hearing showed that $89(58.6 \%)$ patients presented auditory complaints, among them: 18 (20.2\%) reported tinnitus; 27 (30.3\%), hypoacusis and $44(49.4 \%)$ reported both hypoacusis and tinnitus.

The analysis of the results of the tonal threshold audiometry demonstrated the presence of hearing loss in $96(63.2 \%)$ individuals. All losses found were the sensorioneural type, of which 69 (71.9\%) were bilateral, 27 (28.1\%) unilateral, 72 (75\%) symmetrical and 24 (25\%) asymmetrical. Analyzing the ears separately, hearing loss in the right ear (RE) in $80(52.6 \%)$ patients, and in left ear (LE) in 85 (55.9\%).

Related to the analysis of the configuration characteristics of an audiogram, it was found that most of the patients presented normal thresholds to the degree (considering the average frequencies of 0.5 the $4 \mathrm{Kz}$ ), with predominance of flat configuration, for both $\mathrm{RE}$ and LE. High frequencies lightly decreased were observed in approximately $30 \%$ of the ears. It was noted the 
presence of isolated hearing loss in the frequencies of 6 and/or $8 \mathrm{kHz}$ at 24 (30.0\%) patients in the RE and 20 (23.5\%) in LE (table 1).

Comparing the ears, is a statistically significant difference between the average loudness thresholds in most frequencies, with the exception of $250 \mathrm{~Hz}$ and $2 \mathrm{kHz}(p>0.05)$, noting that the low frequencies the right ear has higher averages, and the high frequencies higher averages are in left ear (table 2).

Table 1. Distribution of the number of patients according to the characteristics of hearing loss in the right ear and left ear

\begin{tabular}{|c|c|c|c|c|}
\hline \multirow{3}{*}{ Features } & \multicolumn{4}{|c|}{ Hearing loss } \\
\hline & \multicolumn{2}{|c|}{$\operatorname{RE}(n=80)$} & \multicolumn{2}{|c|}{ LE $(n=85)$} \\
\hline & $\mathrm{n}$ & $\%$ & $\mathrm{n}$ & $\%$ \\
\hline \multicolumn{5}{|l|}{ Degree (average 0.5 to $4 \mathrm{kHz}$ ) } \\
\hline Normal & 53 & 66.3 & 48 & 56.5 \\
\hline Light & 21 & 26.3 & 32 & 37.6 \\
\hline Moderated & 6 & 7.5 & 5 & 5.9 \\
\hline \multicolumn{5}{|l|}{ Isolated loss in $6 \mathrm{kHz}$ and $8 \mathrm{kHz}$} \\
\hline Yes & 24 & 30.0 & 20 & 23.5 \\
\hline No & 56 & 70.0 & 65 & 76.5 \\
\hline \multicolumn{5}{|l|}{ Audiogram configuration } \\
\hline Flat & 44 & 55.0 & 44 & 51.8 \\
\hline High frequencies slightly demoted & 24 & 30.0 & 26 & 30.6 \\
\hline Descendant & 11 & 13.8 & 15 & 17.6 \\
\hline U-shaped average frequency & 1 & 1.3 & 0 & 0 \\
\hline
\end{tabular}

Caption: $\mathrm{RE}=$ right ear; $\mathrm{LE}=$ left ear

Table 2. Comparison of the averages of the tonal airway thresholds of the right ear and the left ear

\begin{tabular}{|c|c|c|c|c|c|}
\hline \multirow{2}{*}{ F (KHz) } & \multicolumn{2}{|c|}{ OD } & \multicolumn{2}{|c|}{$\mathrm{OE}$} & \multirow{2}{*}{ Value of $d$} \\
\hline & Average & s.d. & Average & s.d. & \\
\hline 0.25 & 23.0 & 4.6 & 22.9 & 4.6 & 0.729 \\
\hline 0.5 & 21.4 & 5.2 & 20.3 & 5.4 & 0.001 * \\
\hline 1 & 20.0 & 7.3 & 18.4 & 6.5 & $<* 0.0001$ \\
\hline 2 & 18.7 & 9.0 & 18.2 & 8.8 & 0.428 \\
\hline 3 & 22.1 & 11.6 & 24.1 & 12.5 & 0.001 * \\
\hline 4 & 25.3 & 12.9 & 27.9 & 14.6 & $<* 0.0001$ \\
\hline 6 & 27.6 & 14.7 & 29.3 & 15.8 & 0.049 * \\
\hline 8 & 27.1 & 16.9 & 28.8 & 17.6 & 0.048 * \\
\hline
\end{tabular}

* Significant Values $(p<0.05)$ - Chi-square Test

Caption: $\mathrm{RE}=$ right ear; $\mathrm{LE}=$ left ear; $\mathrm{s} . \mathrm{d} .=$ standard deviation

Otoacoustic emissions analysis was found in 114 (75\%) patients with alterations in TEOAE and in DPOAE 120 (78.9\%). For the RE, TEOAE and DPOAE absence in $86(56.6 \%)$ and in $110(72.4 \%)$ patients, respectively. For the LE, TEOAE and DPOAE absence in 95 (65.2\%) and in $108(71.1 \%)$ patients, respectively.

The average signal/noise relation of frequency bands in the TEOAE and in frequency DPOAE revealed lower values in RE in all tested frequencies, showing greater commitment on the left side. However, statistically, in the frequency bands 1 and $2 \mathrm{kHz}$ the TEOAE, and in the frequencies of $1 ; 1.5 ; 2 ; 5.5$ and $8 \mathrm{kHz}$ in DPOAE, there was no significant difference between the two ears $(p>0.05)$ (table 3$)$.

To analyze the association between PTA and results of the TEOAE, absence of OAE in presence of normal PTA, on average, in $32 \%$ of patients at $48 \%$ RE and LE. Already the presence of OAE in occurrence of hearing loss was observed in approximately $30 \%$ of patients to TEOAE and DPOAE in RE 14\%; and $25 \%$ for TEOAE and DPOAE $11 \%$ on LE (table 4). 
Table 3. Comparison of the averages of the signal/noise of the right ear and the left ear

\begin{tabular}{|c|c|c|c|c|c|}
\hline \multirow{2}{*}{$F(K H z)$} & \multicolumn{2}{|c|}{ RE } & \multicolumn{2}{|c|}{ LE } & \multirow{2}{*}{ Value of $d$} \\
\hline & Average & s.d. & Average & s.d. & \\
\hline \multicolumn{6}{|l|}{ TEOAE } \\
\hline 1 & 12.3 & 7.9 & 11.7 & 7.1 & 0.196 \\
\hline 2 & 12.4 & 7.4 & 11.5 & 7.5 & 0.118 \\
\hline 3 & 7.5 & 7.0 & 6.6 & 6.7 & 0.036 * \\
\hline 4 & 4.8 & 6.5 & 3.2 & 6.1 & * 0.005 \\
\hline \multicolumn{6}{|l|}{ DPOAE } \\
\hline 1 & 10.3 & 5.7 & 10.2 & 5.5 & 0.701 \\
\hline 1.5 & 11.2 & 6.4 & 11.1 & 6.0 & 0.907 \\
\hline 2 & 11 & 5.8 & 10.9 & 5.7 & 0.453 \\
\hline 2.5 & 10 & 5.4 & 8.8 & 6.0 & 0.002 * \\
\hline 3 & 9.9 & 5.5 & 8.9 & 5.7 & 0.008 * \\
\hline 3.2 & 9 & 5.8 & 7.9 & 6.2 & 0.010 * \\
\hline 3.5 & 10.5 & 5.7 & 9.3 & 6.3 & * 0.009 \\
\hline 4 & 11.4 & 6.0 & 9.8 & 6.1 & $<* 0.0001$ \\
\hline 4.5 & 11.8 & 5.9 & 10.9 & 6.3 & * 0.009 \\
\hline 5 & 12.1 & 5.9 & 10.8 & 6.6 & 0.001 * \\
\hline 5.5 & 12 & 6.4 & 11.3 & 6.7 & 0.061 \\
\hline 6 & 11.8 & 6.4 & 10.6 & 6.7 & 0.019 * \\
\hline 7 & 10.8 & 6.7 & 9.8 & 6.9 & 0.042 * \\
\hline 8 & 8.2 & 6.8 & 7.5 & 7.1 & 0.070 \\
\hline
\end{tabular}

* Significant Values $(p<0.05)$ - Chi-square Test

Caption: RE = right ear; $\mathrm{LE}=$ left ear; s.d. = standard deviation; DPOAE = distortion product otoacoustic emissions; TEOA = transient-evoked otoacoustic emissions.

Table 4. Distribution of the number of patients according to the association between the presence of hearing loss and the response of TEOAE and DPOAE in right ear and on the left

\begin{tabular}{|c|c|c|c|c|c|c|c|c|c|c|c|}
\hline & \multicolumn{10}{|c|}{ HEARING LOSS } \\
\hline & & \multicolumn{4}{|c|}{ RE } & \multirow{3}{*}{ p } & \multicolumn{4}{|c|}{ LE } & \multirow{3}{*}{ p } \\
\hline & & \multicolumn{2}{|c|}{ Yes } & \multicolumn{2}{|c|}{ No } & & \multicolumn{2}{|c|}{ Yes } & \multicolumn{2}{|c|}{ No } & \\
\hline & & $n$ & $\%$ & $\mathrm{n}$ & $\%$ & & $\mathrm{n}$ & $\%$ & $n$ & $\%$ & \\
\hline \multirow{2}{*}{ TEOAE } & Present & 21 & 26.3 & 45 & 62.5 & $<* 0.0001$ & 22 & 25.9 & 35 & 52.2 & 0.001 * \\
\hline & Absent & 59 & 73.7 & 27 & 37.5 & & 63 & 74.1 & 32 & 47.8 & \\
\hline \multirow{2}{*}{ DPOAE } & Present & 6 & 7.5 & 36 & 50.0 & $<* 0.0001$ & 10 & 11.8 & 34 & 50.7 & $<* 0.0001$ \\
\hline & Absent & 74 & 92.5 & 36 & 50.0 & & 75 & 88.2 & 33 & 49.3 & \\
\hline
\end{tabular}

* Significant Values $(p<0.05)-$ Chi-square Test

Caption: $\mathrm{RE}=$ right ear; $\mathrm{LE}=$ left ear; TEOAE $=$ transient-evoked otoacoustic emissions.; DPOAE $=$ distortion product otoacoustic emissions

Also, analyses were performed in order to verify a possible association between the variables age and time of diagnosis and the presence of auditory changes. With regard to the age group, it was observed that patients in the range of 51 to 60 years old showed 2.6 times more chance of hearing loss compared to the 36 to 50 years of age. Relating to the time of diagnosis, it was found that patients who were between 13 and 33 years of age DM presented 2.1 times more chance of hearing loss than those who had a diagnosis less than 13 years old (table 5 ).

Finally, analyses were performed in order to verify a possible association between the variables age group and time of diagnosis and the absence of OAE. A relationship was not observed between the age group or the time of diagnosis and the absence of TEOAE (table 6). For the DPOAE, patients with diagnostic time between 13 and 33 years of age presented 2.9 times more likely to have a lack of answers (Table 7). 
Table 5. Distribution of the number of patients according to age-related hearing loss and time of diagnosis

\begin{tabular}{|c|c|c|c|c|c|c|c|}
\hline \multirow{3}{*}{ Variables } & \multicolumn{4}{|c|}{ Hearing loss } & \multirow{3}{*}{ Value of $p$} & \multirow{3}{*}{ RC } & \multirow{3}{*}{$\mathrm{Cl}_{95 \%}$} \\
\hline & \multicolumn{2}{|c|}{ Yes } & \multicolumn{2}{|c|}{ No } & & & \\
\hline & $\mathrm{n}$ & $\%$ & $\mathrm{n}$ & $\%$ & & & \\
\hline \multicolumn{8}{|c|}{ Age group $(n=152)$} \\
\hline $51-60$ & 76 & 69.7 & 33 & 30.3 & 0.008 * & 2.6 & $1.3-5.4$ \\
\hline $36-50$ & 20 & 46.5 & 23 & 53.5 & & & \\
\hline \multicolumn{8}{|c|}{ DM time $(n=151)$} \\
\hline $13-33$ & 40 & 74.1 & 14 & 25.9 & 0.045 * & 2.1 & $1.0-4.3$ \\
\hline $1-12$ & 56 & 57.7 & 41 & 42.3 & & & \\
\hline
\end{tabular}

* Significant Values $(p<0.05)-$ Chi-square Test

Caption: $\mathrm{RC}=$ right of chance; $\mathrm{Cl}=$ confidence interval; $\mathrm{DM}=$ Diabetes Mellitus

Table 6. Distribution of the number of patients according to the absence of TEOAE related to age and time of diagnosis

\begin{tabular}{|c|c|c|c|c|c|c|c|}
\hline \multirow{3}{*}{ Variables } & \multicolumn{4}{|c|}{ Absence TEOAE } & \multirow{3}{*}{ Value of $p$} & \multirow{3}{*}{ RC } & \multirow{3}{*}{$\mathrm{Cl}_{95 \%}$} \\
\hline & \multicolumn{2}{|c|}{ Yes } & \multicolumn{2}{|c|}{ No } & & & \\
\hline & $\mathbf{n}$ & $\%$ & $\mathrm{n}$ & $\%$ & & & \\
\hline Age group $(n=152)$ & & & & & & & \\
\hline $51-60$ & 83 & 76.1 & 26 & 23.9 & 0.603 & 1.2 & $0.5-2.9$ \\
\hline $36-50$ & 31 & 72.1 & 12 & 27.9 & & & \\
\hline DM time $(n=151)$ & & & & & & & \\
\hline $13-33$ & 42 & 77.8 & 12 & 22.2 & 0.534 & 1.3 & $0.5-3.1$ \\
\hline $1-12$ & 71 & 73.2 & 26 & 26.8 & & & \\
\hline
\end{tabular}

* Significant Values $(p<0.05)-$ Chi-square Test

Caption: TEOAE = transient-evoked otoacoustic emissions; $\mathrm{RC}=$ right of chance; $\mathrm{Cl}=$ confidence interval; $\mathrm{Dm}=$ Diabetes Mellitus.

Table 7. Distribution of the number of patients according to the absence of DPOAE related to age group and time of diagnosis

\begin{tabular}{|c|c|c|c|c|c|c|c|}
\hline \multirow{3}{*}{ Variables } & \multicolumn{4}{|c|}{ Absence DPOAE } & \multirow{3}{*}{ Value of $p$} & \multirow{3}{*}{$\mathrm{RC}$} & \multirow{3}{*}{$\mathrm{Cl}_{95 \%}$} \\
\hline & \multicolumn{2}{|c|}{ Yes } & \multicolumn{2}{|c|}{ No } & & & \\
\hline & $\mathrm{n}$ & $\%$ & $n$ & $\%$ & & & \\
\hline \multicolumn{8}{|c|}{ Age group $(n=152)$} \\
\hline $51-60$ & 90 & 82.6 & 19 & 17.4 & 0.081 & 2 & $0.8-5.0$ \\
\hline $36-50$ & 30 & 69.8 & 13 & 30.2 & & & \\
\hline \multicolumn{8}{|c|}{ DM time $(\mathrm{n}=151)$} \\
\hline $13-33$ & 48 & 88.9 & 6 & 11.1 & 0.024 * & 2.9 & $1.1-9.3$ \\
\hline $1-12$ & 71 & 73.2 & 26 & 26.8 & & & \\
\hline
\end{tabular}

* Significant Values $(p<0.05)-$ Chi-square Test

Caption: $\mathrm{DPOAE}=$ distortion product otoacoustic Emissions; $\mathrm{RC}=$ right of chance; $\mathrm{Cl}=$ confidence interval; $\mathrm{DM}=$ Diabetes Mellitus.

\section{DISCUSSION}

In the present study we could observe the prevalence of diabetic patients ranging in age from 51 to 60 years, with the age-associated hearing loss. There was no association of age with the absence of responses in the OAE. Some studies involving individuals with older age, observed the relation of DM with the hearing loss ${ }^{14,}$ ${ }_{18,23}$ and with the absence of $O A E^{2}$, while others found no association ${ }^{15,24}$.
Considering the prevalence and severity of hearing loss increases significantly with $\operatorname{age}^{18}$, the positive association could be related to presbycusis, however, the association was found with auditory changes even in a sample of diabetic patients, with up to 50 years of age $^{25}$.

The time of diagnosis of the disease was another factor associated with hearing loss and, in this case, the absence of DPOAE. The direct relationship between duration of DM and hearing loss was also reported by 
Sunkum et al. ${ }^{9}$ Other authors showed no association between the duration of the illness and the alterations in PTA or $\mathrm{OAE}^{2,14,25,26}$, however, it should be noted that in two of these studies ${ }^{2,25}$ the sample evaluated presented recent diagnosis, up to 7 years.

Mitchell et al. ${ }^{23}$ results found in a consistent cross association between the duration of diabetes and hearing loss, revealing that in 5 years, there was an accelerated progression of deafness in patients early diagnosed with DM. However, in the same study, people with previously diagnosed diabetes showed a non-significant inverse association with the progression of hearing loss. The authors suggest that the early diagnosis and treatment for the DM can avoid potential fall in the hearing, giving a protective effect.

Hearing complaints such as tinnitus and hypocusis, present in 89 (58.8\%) patients, seem common in diabetics, being cited, to a greater or lesser frequency in many studies relating hearing and $\mathrm{DM}^{12,13,25}$. According to Gibrin et al. ${ }^{27}$, changes in the inner ear, causing Vertigo and/or tinnitus, hearing loss, can be related to a microcirculatory failure due to a vascular occlusion by emboli, hemorrhage or Vasospasm, and these, in turn, would be due to hyper viscosity or microangiopathy by DM or hypertension.

Relating to the audiometric findings, the hearing loss was observed in $63.2 \%$ of patients evaluated, being all of the sensorioneural type, with a predominance of bilateral and symmetrical losses. Similar results were found in other studies ${ }^{25,28}$.

Sunkum et al. ${ }^{9}$ found prevalence of hearing loss in $58.3 \%$ of patients with controlled glucose and $85.2 \%$ of diabetic patients with uncontrolled glucose levels, corroborating with the hypothesis that the glucose control can protect against hearing deficiency ${ }^{23,29}$. Study realized in diabetic patients with early diagnosis (before 40 years old) showed prevalence of $21.7 \%$ sensorioneural uni or bilateral hearing loss, stating that the type 2 DM early start and with poor glycemic control leads to an increased prevalence of subclinical hearing loss and prejudice in the responses of the brain stem ${ }^{13}$. In the present study the glycemic control of patients was not evaluated, so it is not possible to infer about its relation with the hearing loss.

On the audiogram characterization of this study a greater number of ears with degree considered normal were found, however, the degree classification only takes into consideration the frequencies of 0.5 to 4 $\mathrm{kHz}{ }^{19}$, and were found in isolated hearing loss in the frequencies of 6 and/or $8 \mathrm{kHz}$. This fact explains why many losses were classified as normal hearing degree. The losses encountered, lightweight degree prevailed flat configuration.

The audiometric configuration of patients with DM offers great variation between the authors. Some studies point out the loss attributed to the DM as the sensorioneural bilateral type, affecting mainly high frequencies $9,12,13,15,25,28$; others have found worse thresholds at low frequencies ${ }^{30}$, low and medium-sized ${ }^{14}$ or low and high ${ }^{2}$; and some refer to predominant ${ }^{14}$ flat configuration. As for the degree, most research concerns take hearing loss on the $\mathrm{DM}^{12,13,18,25,28}$.

Analyzing the frequencies specifically, it was observed that the frequencies above $4 \mathrm{kHz}$ were most affected in patients evaluated. Other authors also reported worse thresholds in $4 \mathrm{kHz}^{26}$ and in 4 and $8 \mathrm{kHz}^{10}$.

The predominance of high frequency alterations can be related to presbycusis, characterized by highfrequency symmetric bilateral sensorioneural loss ${ }^{27}$, whereas studies involving elderly diabetic patients ${ }^{18,23}$. Some authors suggest that the DM mechanisms could act synergistically with the underlying processes related hearing loss with age, resulting in worsening of hearing ${ }^{2,23}$. However, other studies ${ }^{9,13}$ evaluated younger diabetic patients (up to 50 years of age) and found the same characteristics of hearing, contradicting the theory that the loss could be merely a phenomenon attributed to age.

The results are quite contradictory, as there are studies with individuals with up to 69 years old who have a predominance of flat configuration ${ }^{14}$, similar to what was found in the results of this study. There was no consensus in the literature study on the characteristics of hearing loss associated with the DM; it is believed that the variations found could be related to inner ear affected region. Although many studies point to the existence of histopathological cochlear alterations in DM, it is difficult to establish a causal relationship, highlighting the differential vulnerability of inner ear to the effects of hyperglycemy ${ }^{5}$.

The analysis of the OAE TEOAE and DPOAE showed absence in more than $70 \%$ of patients. A similar result was found for Prabhu et al. ${ }^{31}$, which revealed the absence of TEOAE in $68 \%$ in patients with type 2 DM, 40-60 years of age. The same study also showed decreased amplitude of DPOAE and TEOAE, as well as damage to the efferent system. Other studies, involving diabetic patients with up to 70 years of age, also found reduced amplitude inTEOAE and $\mathrm{DPOAE}^{2,15}$. 
Conflicting findings have been found in other studies. Agarwal et al. ${ }^{25}$ found absence of TEOAE on $30 \%$ of the samples, and Lerman-Garber et al. ${ }^{13}$ in just $15 \%$, but in both studies, patients evaluated were younger diabetics (ages up to 50 years old) and the audiometric findings revealed the prevalence of mild loss, which can justify the greater number of TEOAE present, since the presence of TEOAE on most individuals correlates with the degree of loss, and may be obtained in hearing loss less than $40 \mathrm{~dB}^{25}$. Eren et al. ${ }^{16}$ analyzed the TEOAE and DPOAE in DM patients, average age of 47 years and normal hearing, and, although it was found decreased amplitude, the difference between the DM and the control group was not statistically significant.

The relationship between auditory alterations found and the affected side was described in the results, showing a greater tendency of left-side commitment to high frequencies in PTA, in TEOAE and DPOAE, and, although the difference is not significant in some frequencies. Evidence on laterality dominant in auditory changes in patients with DM was not found in the literature. However, some authors have mentioned greater commitment from the right side in their findings related to audiometry ${ }^{28,30}$. Others have not showed a predominance of tonal thresholds ${ }^{25}$. Karabulut et al. ${ }^{15}$, analyzing the OAE, also did not pointed out the difference between the sides. Frisina et al. ${ }^{30}$, when realized the DPOAE, right commitment was found, $\mathrm{Cabrer}^{28}$ to the left.

The analysis of correlation between hearing loss and the result of the TEOAE and DPOAE, it was observed that the percentage of TEOAE and DPOAE alterations is greater than the percentage of patients with hearing loss, showing that the emissions can be altered even with audibility thresholds within the normal range, which supposes a cochlear impairment in $\mathrm{DM}^{22}$. Metabolic changes caused by the DM can modify the micromechanism of the inner ear, causing subclinical early results ${ }^{2}$. It is evident the importance of the OAE as clinical instrument for monitoring the cochlea, for allowing the subtle detection of cochlear alteration observed in PTA, being suggestive its indication for evaluation of auditory functions in DM.

The presence of TEOAE and DPOAE on hearing loss may be related to the degree of loss found; being mostly light degree, and it still favors the appearance of otoacoustic emission answers ${ }^{22}$. The OAE presence in patients with hearing loss also could assume cases of auditory neuropathy, characterized by a specific hearing disorder with abnormal auditory neural responses in the presence of normal cochlear function ${ }^{32}$. Considering the DM can cause degeneration of the auditory nerve ${ }^{6}$, specific tests for assessment of central auditory system would be essential for the differential diagnosis.

The difference between the results of two types of emissions can be linked to the fact of DPOAE assess the frequencies of 6 and $8 \mathrm{kHz}$, in which there are isolated losses, causing the occurrence of DPOAE absent is larger.

This study has some limitations, such as the absence of a control group, which would allow for comparative analysis; and the absence of data related to glycemic control, which presented itself as a risk factor associated with auditory changes in many studies cited.

\section{CONCLUSION}

Assessment of hearing in type 2 diabetic patients showed a predominance of sensorioneural symmetric bilateral hearing loss with flat configuration. The absence of TEOAE and DPOAE was observed in most patients.

The absence of OAE before normal audio thresholds, present in part of the sample, suggests prejudice to the ciliated cells of the external cochlea. Such findings may indicate early cochlear dysfunction in type $2 \mathrm{DM}$, what would justify the hearing monitoring of these patients.

The OAE presence in patients with hearing loss could be related to the light degree attempt, found in most cases, or might suggest cases of auditory neuropathy. In this way, specific tests for assessment of central auditory system would be relevant to indicate the audiologic diagnosis of patients with type $2 \mathrm{DM}$.

The knowledge of the effects of DM over hearing favors early intervention, minimizing the prejudice and amplifying the quality of life.

\section{ACKNOWLEDGEMENTS}

To the Fundação Cearense de Apoio ao Desenvolvimento Científico e Tecnológico (FUNCAP) for funding for the implementation of the research.

To the Centro Integrado de Diabetes e Hipertensão de Fortaleza for the support to the develop of this reserch. 


\section{REFERENCES}

1. Brasil. Secretaria de Atenção à Saúde. Departamento de Atenção Básica. Estratégias para o cuidado da pessoa com doença crônica: diabetes mellitus. Brasília: Ministério da Saúde; 2013.

2. Abo-Elfetoh NM, Mohamed ES, Tag LM, El-Baz MA, Eldeen MEE. Auditory dysfunction in patients with type 2 diabetes mellitus with poor versus good glycemic control. Egypt J Otolaryngol. 2015; 31(3): 162-9.

3. International Diabetes Federation. IDF Diabetes Atlas. 7ed. Brussels, Belgium: International Diabetes Federation; 2015.

4. Hong O, Buss J, Thomas E. Type 2 diabetes and hearing loss. Disease-a-Month. 2013; 59(4): 139-46.

5. Akinpelu OV, Ibrahim F, Waissbluth S, Daniel SJ. Histopathologic changes in the cochlea associated with diabetes mellitus-a review. Otol Neurotol. 2014; 35(5): 764-74.

6. Rolim LP, Rabelo CM, Lobo IFN, Moreira RR, Samelli AG. Interação entre diabetes mellitus e hipertensão arterial sobre a audição de idosos. CoDAS 2015; 27(5): 428-32.

7. Horikawa C, Kodama S, Tanaka S, Fujihara K, Hirasawa R, Yachi $Y$ et al. Diabetes and risk of hearing impairment in adults: a meta-analysis. J Clin Endocrinol Metab. 2012; 98(1): 51-8.

8. Akinpelu OV, Mujica-Mota M, Daniel SJ. Is type 2 diabetes mellitus associated with alterations in hearing? A systematic review and meta-analysis. Laryngoscope. 2014; 124(3): 767-76.

9. Sunkum AJK, Pingile S. A clinical study of audiological profile in diabetes mellitus patients. Eur Arch Otorhinolaryngol. 2013; 270(3):875-9.

10. Ren J, Zhao P, Chen L, Xu A, Brown S, Xiao X. Hearing loss in middle-aged subjects with type 2 diabetes mellitus. Arch Med Res. 2009;40(1) suppl 1:18-23.

11. Lin SW, Lin YS, Weng SF, Chou CW. Risk of developing sudden sensorineural hearing loss in diabetic patients: a population-based cohort study. Otol Neurotol. 2012; 33(9): 1482-8.

12. Ferreira JM, Sampaio FMO, Coelho JMS, Almeida NMGS. Perfil audiológico de pacientes com diabetes mellitus tipo 2. Rev Soc Bras Fonoaudiol. 2007;12(4):292-7.
13. Lerman-Garber I, Cuevas-Ramos D, Valdés $S$, Enríquez L, Lobato $M$, Osornio $M$ et al. Sensorineural hearing loss-A common finding in early-onset type 2 diabetes mellitus. Endocr Pract. 2012; 18(4): 549-57.

14. Bamanie AH, Al-Noury Kl. Prevalence of hearing loss among Saudi type 2 diabetic patients. Saudi Med J. 2011; 32(3): 271-4.

15. Karabulut H, Karabulut I, Dağli M, Bayazit YA, Bilen Ş, Aydin $Y$ et al. Evaluation of outer hair cell function and medial olivocochlear efferent system in patients with type II diabetes mellitus. Turk J Med Sci. 2014; 44(1): 150-6.

16. Eren E, Harman E, Arslanoğlu S, Önal K. Effects of Type 2 Diabetes on Otoacoustic Emissions and the Medial Olivocochlear Reflex. Otolaryngol Head Neck Surg. 2014; 150(6): 1033-9.

17. Calvin D, Watley SR. Diabetes and hearing loss among underserved populations. Nurs Clin N Am. 2015; 50(3): 449-56.

18. Oh I-H, Lee JH, Park DC, Kim M, Chung JH, et al. Hearing Loss as a Function of Aging and Diabetes Mellitus: A Cross sectional Study. PLoS one. 2014; 9(12): e116161.

19. Russo ICP, Pereira LD, Carvalho RMM, Anastásio ART. Encaminhamentos sobre a classificação do grau de perda auditiva em nossa realidade. Rev Soc Bras Fonoaudiol. 2009; 14(2): 287-8.

20. Demeester K, Wieringen A, Hendrickx J, Topsakal $V$, Fransen E, Laer $L$ et al. Audiometric shape and presbycusis. Int J Audiol. 2009; 48(4) suppl I: 222-32.

21. Mattos LC, Veras RP. Prevalência da perda auditiva em uma população de idosos da cidade do Rio de Janeiro: um estudo seccional. Braz J Otorhinolaryngol. 2007;73(5):654-9.

22. Sousa LCA, Piza MRT, Alvarenga KF, Cóser PL. Emissões Otoacústicas. In: Eletrofisiologia da audição e emissões otoacústicas: princípios e aplicações clínicas. 2ed. São Paulo: Tecmedd; 2008. p.109-30.

23. Mitchell $P$, Gopinath $B$, McMahon CM, Rochtchina E, Wang JJ, Boyages SC, Leeder SR. Relationship of Type 2 diabetes to the prevalence, incidence and progression of age-related hearing loss. Diabet Med. 2009; 26(5): 483-8.

24. Konrad-Martin D, Reavis KM, Austin D, Reed N, Gordon J, McDermott D, Dille MF. Hearing impairment in relation to severity of diabetes in a veteran cohort. Ear Hear. 2015;36(4):381-94. 
25. Agarwal AC, Pujary K, Ganapathy K, Balakrishnan $R$, Nayak DR, Hasan F. Pure tone audiometry and otoacoustic emissions for the assessment of hearing loss in diabetic patients. Indian J Otol. 2013;19(1):13.

26. Salvinelli F, Miele A, Casale M, Greco F, D'Ascanio $L$, Firrisi $L$ et al. Hearing thresholds in patients with diabetes. Int $\mathrm{J}$ Otorhinolaryngol. [serial online]. 2004 [acesso em 29/10/2015];3(1). Disponível em: http://www.ispub.com/journal/the-internetjournal-of-otorhinolaryngology/volume-3-number-1/ hearing-thresholds-in-patients-with-diabetes.html

27. Gibrin PCD, Melo JJ, Marchiori LLDM. Prevalência de queixa de zumbido e prováveis associações com perda auditiva, diabetes mellitus e hipertensão arterial em pessoas idosas. CoDAS . 2013; 25(2): 176-80.

28. Cabrer IS. Otoemissiones acusticas em pacientes diabeticos no insulinodependientes. [Tese]. Barcelona: Hospital Universitario de Girona - Doctor Josep Trueta; 2006.

29. Michikawa T, Mizutari K, Saito H, Takebayashi T, Nishiwaki Y. Glycosylated hemoglobin level is associated with hearing impairment in older Japanese: The Kurabuchi study. J Am Geriatr Soc. 2014; 62(7): 1231-7.

30. Frisina ST, Mapes F, Kim S, Frisina DR, Frisina RD. Characterization of hearing loss in aged type II diabetes. Hear Res. 2006; 211(1/2)suppl I:103-13.

31. Prabhu P, Shanthala SP. Efferent Auditory System Functioning and Speech Perception in Noise in Individuals with Type II Diabetes Mellitus. J Phonet Audiol. 2016;2:115.

32. Braite N, Fernandes LC, Andrade CLO, Alves CAD. Neuropatia auditiva no diabetes melito tipo 1: relato de caso. Rev Cienc Med Biol. 2014;13(3):438-42. 